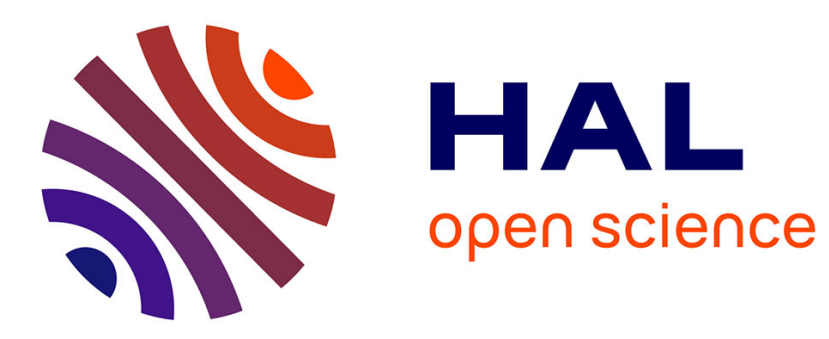

\title{
Colossal Magnetoresistance of La-Ca-Mn-O Films
}

M. Kitagawa, T. Namikawa, Y. Yamazaki

\section{To cite this version:}

M. Kitagawa, T. Namikawa, Y. Yamazaki. Colossal Magnetoresistance of La-Ca-Mn-O Films. Journal de Physique IV Proceedings, 1997, 07 (C1), pp.C1-641-C1-642. 10.1051/jp4:19971265 . jpa-00254975

\section{HAL Id: jpa-00254975 https://hal.science/jpa-00254975}

Submitted on 1 Jan 1997

HAL is a multi-disciplinary open access archive for the deposit and dissemination of scientific research documents, whether they are published or not. The documents may come from teaching and research institutions in France or abroad, or from public or private research centers.
L'archive ouverte pluridisciplinaire HAL, est destinée au dépôt et à la diffusion de documents scientifiques de niveau recherche, publiés ou non, émanant des établissements d'enseignement et de recherche français ou étrangers, des laboratoires publics ou privés. 


\title{
Colossal Magnetoresistance of La-Ca-Mn-O Films
}

\author{
M. Kitagawa, T. Namikawa and Y. Yamazaki \\ Interdisciplinary Graduate School of Science and Engineering, Tokyo Institute of Technology, 4259 \\ Nagatsuta, Midori-ku, Yokohama 226, Japan
}

\begin{abstract}
We have investigated the magnetoresistance and magnetization of the thin films of $\mathrm{LaCa}_{0.25} \mathrm{Mn}_{1.2} \mathrm{O}_{3+8}$. The films were prepared by rf-sputtering at $650^{\circ} \mathrm{C}$ on single crystal $\mathrm{LaAlO}_{3}(100), \mathrm{MgO}(100)$ and rough $\mathrm{MgO}$ surfaces, with a thickness of 480 $\mathrm{nm}$, and they were thermally treated at $1050^{\circ} \mathrm{C}$. The dependence of the magnetoresistance on the grown conditions such as substrate materials and the surface roughness of the substrate was examined. The significant magnetoresistance appeared at different temperatures when the film epitaxy changed.
\end{abstract}

\section{Introduction}

Calcium doped lanthanum manganite $\left(\mathrm{La}_{(1-x)} \mathrm{Ca}_{x} \mathrm{MnO}_{3}\right)$ shows a large magnetoresistance. This material is expected to be applied for various magnetic devices. The large magnetoresistance of the thin film occur near the temperature where as metal-semiconductor transition takes place. The transition temperature is strongly dependent on the deposition conditions of the film. We have investigated the influence of substrate conditions on the magnetic and electric properties of the films.

\section{Experimental}

La-Ca-Mn-O films $\left(\mathrm{a}_{0}=3.85 \AA\right)$ were deposited by rf sputtering at $650^{\circ} \mathrm{C}$ on $\mathrm{MgO}(100)\left(\mathrm{q}_{\mathrm{o}}=4.20 \AA\right)$ single crystal substrates, and on $\mathrm{MgO}$ rough surface substrates which were ground with a diamond paste of \#1200. The sputtering conditions are given in Table 1. The size of the films was $4 \times 7 \mathrm{~mm}$ and thickness was $480 \mathrm{~mm}$. The deposited films were thermally treated at $1050^{\circ} \mathrm{C}$ in air for $5 \mathrm{~h}$. The resistance of the films was measured by 2 point method with a direct current of about $100 \mu \mathrm{A}$ and a magnetic field of $9 \mathrm{kOe}$ in the temperature range from $77 \mathrm{~K}$ to room temperature. Magnetization was measured in a field of $0.5 \mathrm{kOe}$ or $8 \mathrm{kOe}$ with a high sensitivity VSM in the same temperature range. The MR ratio is defined as $\Delta R / R_{\mathrm{H}}$ where $\Delta R=\left(R_{\mathrm{H}}-R_{0}\right)$ and $R_{\mathrm{H}}$ is the resistance at an applied magnetic field of $9 \mathrm{kOe}$, and $R_{0}$ is the resistance without magnetic field. The thickness of the films was measured using a surface step analyzer (DEKTAK ${ }^{3} \mathrm{ST}$ ). The chemical composition of the films was determined by inductively coupled plasma spectroscopy. The surface of substrate was observed with a SEM. The films were examined by $\mathrm{X}$-ray diffraction.

Table 1. Sputtering conditions.

\begin{tabular}{|c|c|}
\hline $\begin{array}{l}\text { Target } \\
\text { Sputter gas } \\
\text { Base pressure } \\
\text { Sputter pressure } \\
\text { Substrate }\end{array}$ & $\begin{array}{l}\mathrm{La0.6} \times \mathrm{Ca} 0.33 \mathrm{MnO} \\
\mathrm{Ar}: \mathrm{O} 2=3: 2 \\
1.1 \times 10^{-3} \mathrm{~Pa} \\
8.0 \mathrm{~Pa} \\
\mathrm{LaAlO}(100) \\
\mathrm{MgO}(100) \\
\mathrm{MgO} \text { rough } \\
650^{\circ} \mathrm{C}\end{array}$ \\
\hline Input power & $2.5 \mathrm{~W} / \mathrm{cm}^{2}$ \\
\hline
\end{tabular}

Table 2. Preparation conditions of sample films

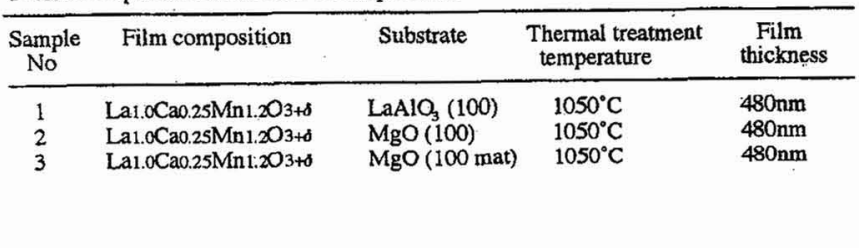




\section{Results and Diseussion}

Table 2 shows the film compositions, substrates and temperatures of thermal treatment. The film compositions are normalized by lanthanum contents. Figures $2-4$ show the $\mathrm{MR}$ ratio $\Delta R / R_{\mathrm{H}}(\%)$, magnetization $M$ measured in a field of $0.5 \mathrm{kOe}$ and resistivity $\rho$ of the films. The metal-semiconductor transition is observed in Samples 1 and 2, and substantial magnetoresistance appears in the metallic conduction region near the transition temperature. The MR ratio is about $-20 \%$. A larger MR ratio of $-175 \%\left(\rho_{0}=11.9 \Omega \mathrm{cm}, \rho_{\mathrm{H}}=32.7 \Omega \mathrm{cm}\right)$ was observed at $9 \mathrm{kOe}$ at $108 \mathrm{~K}$ with an LCMO film which was deposited on $\mathrm{MgO}(100)$ with the composition of $\mathrm{La}_{1.0} \mathrm{Ca}_{0.35} \mathrm{Mn}_{1.1} \mathrm{O}_{3+5}$. The magnetoresistance appeared only in the films which show the metal-semiconductor transition. Above the transition temperature, a linear relation was obtained between log $\sigma$ and $1 / T$, where $\sigma$ is the conductivity of the films and $T$ is temperature.

The magnetization reduces with temperature in all the samples. The temperature of the metal-semiconductor transition corresponds considerably to the temperature at which the magnetization disappears in Samples 1 and 2 . The magnetization curve of Sample 1 have a shoulder at about $240 \mathrm{~K}$. In Sample 1 the $\rho-T$ curve is sharp and the magnetization disappears at the transition temperature. Samples 1 and 2 are different in substrate material. There is a difference in lattice mismatch between film and substrate. The temperature range where the magnetoresistance appears is wider in Sample 2 than in Sample 1 . It is expected that the larger lattice mismatch brings about the magnetoresistance in the wider temperature range.

Samples 2 and 3 are different in the roughness of the substrate surface. The roughness of the substrate of Sample 3, which was measured with a SEM, was about $100 \mathrm{~nm}$. Sample 3 shows neither metal-semiconductor transition nor magnetoresistance. The resistivity of Sample $\mathbf{3}$ at room temperature is $\mathbf{2 0}$ times as large as that of Sample 2. The resistivity of Sample 3 increases sharply below $150 \mathrm{~K}$. The temperature dependence of magnetization in Sample 3 does not differ from that in Sample 2. In conclusion, we consider that the CMR of thin films strongly depends on the surface structure of the substrate. The authors are grateful to Dr. H. Nishio, TDK corporation for measured magnetic properties at a low temperature.

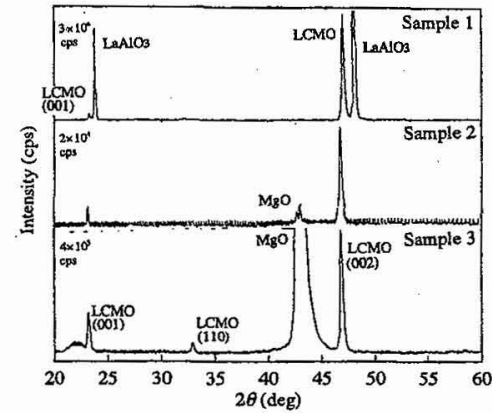

Fig.1. X-ray diffraction patterns of the LCMO films grown on different substrates.

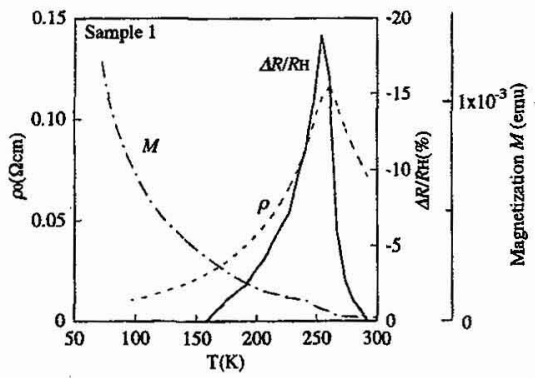

Fig.2. $\Delta R / R_{\mathrm{H}}, \rho$ and $M$ vs. temperature for $\mathrm{La}_{1.0} \mathrm{Ca}_{0.25} \mathrm{Mn}_{1.15} \mathrm{O}_{3+\delta}$ film deposited on $\mathrm{LaAlO}_{3}(100), H=9 \mathrm{kOe}$.

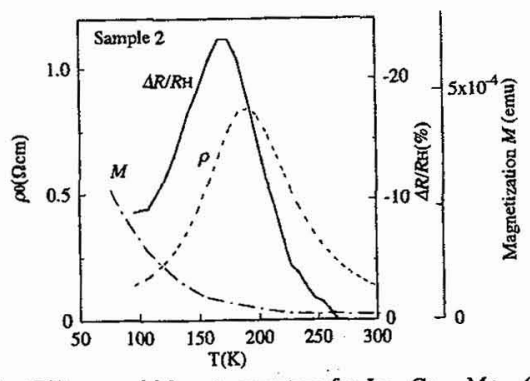

Fig.3. $\Delta R / R_{\mathrm{H}} \rho$ and $M$ vs, temperature for $\mathrm{La}_{1.0} \mathrm{Ca}_{0.25} \mathrm{Mn}_{1.15} \mathrm{O}_{3+8}$ film deposited on $\mathrm{MgO}(100), H=9 \mathrm{kOe}$.

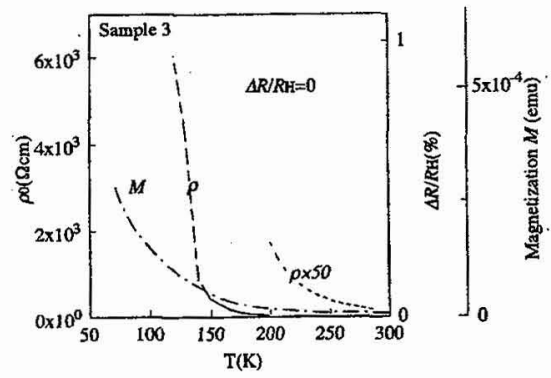

Fig.4. $\Delta R / R_{\mathrm{H}} \rho$ and $M$ vs. temperature for $\mathrm{La}_{1,} \mathrm{Ca}_{0.25} \mathrm{Mn}_{1.15} \mathrm{O}_{3+8}$ film deposited on $\mathrm{MgO}$ rough, $H=9 \mathrm{kOe}$.

\section{Reference}

1) S. Jin, T. H. Tiefel, M. McCormack, R. A. Fastnacht, R. Ramesh, L. H. Chen, Science 264, 413-415 (1994)

2) M. Kitagawa and Y. Yamazaki, J. Magn. Soc. Jpn. , in press 